\title{
Informes de sostenibilidad y planes de vigilancia: explorando nuevos caminos para luchar contra la impunidad empresarial
}

\author{
Sustainability Reports and Vigilance Plans: \\ Exploring New Ways to Fight Corporate Impunity ${ }^{1}$ \\ Lorena Sales Pallarés \\ Universidad de Castilla-La Mancha \\ Lorena.Sales@uclm.es \\ Maria Chiara Marullo \\ Universitat Jaume I \\ marullo@uji.es
}

Sumario: I. Introducción.-II. La obligación de diligencia debida (reporting). 1. El uso del reporting en algunas normas supranacionales. 2. La utilización del reporting en un plano nacional.-III. Abriendo nuevos caminos desde reflexiones críticas sobre lo existente y lo venidero.-IV. Conclusiones.

Resumen: El propósito de este trabajo es seguir avanzando en el tema de las Empresas y los Derechos Humanos, área temática que ha adquirido mucha trascendencia en las relaciones transfronterizas y que puede plantear nuevas líneas de investigación actualmente poco exploradas. En este artículo reflexionamos sobre el potencial que tiene la nueva política de transparencia empresarial, propiciada por las normas relativas a la obligación de la publicación de la información no financiera, prácticas de esclavitud moderna o de planes de vigilancia. Las obligaciones de vigilancia y de reporting, podrían permitir superar las barreras de derecho mercantil para lograr un concepto unitario de grupo empresarial y por tanto responsabilizar a la matriz por falsear la información y por no haber controlado debidamente las actividades de las empresas que pertenecen a su grupo. Al mismo tiempo, estos deberes podrían abrir nuevos foros para otras empresas y para los consumidores afectados por la falsedad u omisión de la información presentada. Un paso, útil, necesario y complementario para poner fin a la impunidad de estos entes transnacionales.

${ }^{1}$ Este artículo ha sido preparado en el marco del Proyecto CONCLIMA. Proyecto financiado por el Ministerio de Economía y Competitividad. Período 2017-2019. DER201680011-P. 
Palabras clave: Empresas y derechos humanos, informes de sostenibilidad, planes de vigilancia, reporting, esclavitud moderna.

Abstract: The purpose of this work is to continue advancing the topic of Business and Human Rights, a thematic area that has acquired much importance in cross-border relations and that may pose new lines of research currently underexplored. In this article we reflect on the potential of the new policy of corporate transparency, fostered by the rules regarding the obligation to publish nonfinancial information, modern slavery practices or vigilance plans. Monitoring and reporting obligations could help to overcome commercial law barriers to a unitary concept of corporate groups and therefore make the parent company responsible for misrepresentation and failure to properly control the activities of companies belonging to its group. At the same time, these duties could open up new forums for other companies and for consumers affected by the misrepresentation or omission of the information presented. This is a useful, necessary and complementary step to put an end to the impunity of these transnational entities.

Keywords: Business and human rights, sustainability reports, vigilance plans, reporting, modern slavery

\section{Introducción}

El análisis que se propone en este artículo toma como eje central los informes relativos a la información no financiera y los planes de vigilancia ${ }^{2}$, propiciados por las recientes prácticas legislativas que se fundamentan en el concepto de debida diligencia, due diligence ${ }^{3}$, y sus impactos en los merca-

2 Para una aproximación a estos conceptos puede consultarse Julita García Diez y Pilar Sáenz de Jubera Álvarez, «Información no financiera: memorias e informes de sostenibilidad», en La contabilidad al servicio de la empresa y de la sociedad: homenaje al profesor Antonio López Díaz (Oviedo: Universidad de Oviedo, Ediciones de la Universidad de Oviedo, 2016): 127-148; Nélida Porto Serantes, «Tendencias en la información no financiera para la gestión de la empresa socialmente responsable», Revista iberoamericana de contabilidad de gestión, n. 5 (2005): 13-44; Carlos de Miguel Perales, «Hacia una mayor transparencia: divulgación de información no financiera y sobre diversidad», Actualidad jurídica Uría Menéndez, n. ${ }^{\circ} 49$ (2018): 141-149, https://www.uria.com/documentos/publicaciones/5896/ documento/art012.pdf?id=8348.

${ }^{3}$ Para un estudio más en extenso sobre este concepto nos remitimos a Olga Martín Ortega y Johanna Hoekstra, «Reporting as a Means to Protect and Promote Human Rights? The EU Non-Financial Reporting Directive», EuropeanLawReview, n. ${ }^{\circ}$ (2019):622-645; Olga Martín Ortega, «La diligencia debida de las empresas en materia de Derechos Humanos: un nuevo estándar para una nueva responsabilidad», en La responsabilidad de las multinacionales por violaciones de derechos humanos, eds. por Francisco Javier Zamora Cabot, Jesús García Cívico y Lorena Sales Pallarés (Alcalá de Henares: Universidad de Alcaláde Henares, 2013), 167-192; Nicolás Bueno, «Diligence en matière de droits de l'homme et responsabilité de l'entreprise: Le point en droit- 
dos, para avanzar en la propuesta de nuevos foros que legitimen a nuevos sujetos de derecho, como pueden ser los consumidores, para responsabilizar a las corporaciones por las graves violaciones sobre los derechos humanos en general y contra el medio ambiente en particular, pero partiendo de la información que estas empresas han publicado sobre sus propias actuaciones, en el marco de la debida diligencia.

En el marco de las relaciones entre empresas y derechos humanos, la debida diligencia la debemos entender como el proceso mediante el cual se identifican los riesgos y se gestionan los impactos negativos que el desempeño de una actividad empresarial puede tener, en términos de derechos humanos y protección del medio ambiente, y que se extiende transversalmente desde la extracción de las materias primas hasta la venta de los productos ${ }^{4}$.

Algunos autores se han referido a la debida diligencia como el «grado razonable de prudencia ejercido por una empresa». [...] La Debida Diligencia en Derechos Humanos se refiere tanto al «proceso» (la forma en que hacemos las cosas) como a los «resultados» (los resultados logrados). Desde una perspectiva de Derechos Humanos, resultan fundamentales los métodos que las empresas utilizan para involucrar a los individuos o comunidades, teniendo en cuenta que éstas pueden impactar en sus derechos humanos.» ${ }^{5}$

De acuerdo con la texto elaborado por el Grupo de trabajo sobre Empresas y Derechos Humanos de las Naciones Unidas ${ }^{6}$, la due diligence «in-

suisse», Schweizerische Zeitschrift für internationales und europäisches Recht $=$ Revuesuisse de droitinternational et droiteuropéen, Vol. 29, n. ${ }^{\circ} 3$ (2019): 345-366; Adoración Guamán Hernández, «Diligencia debida en derechos humanos y empresas transnacionales: de la ley francesa a un instrumento internacional jurídicamente vinculante sobre empresas y derechos humanos», Lex social: revista de los derechos sociales, n. $^{\circ} 2$ (2018): 216-250; Maria Eugenia Hernández Peribañez, «Empresas transnacionales y esclavitud moderna en la cadena de suministro textil: implementación de la debida diligencia y sus efectos en el acceso a mecanismos de reparación judicial» (tesis doctoral, Universitat de València, 2017), https://www.educacion.gob.es/teseo/imprimirFicheroTesis.

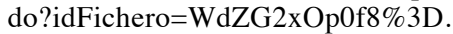

${ }^{4}$ Más información sobre el concepto de debida diligencia en el tema de las Empresas y los Derechos Humanos: Principios Rectores Empresas y Derechos Humanos, en: https:// www.ohchr.org/documents/publications/guidingprinciplesbusinesshr_sp.pdf.

${ }^{5}$ Centro Regional de Empresas y Emprendimientos Responsables (CREER), debida diligencia en derechos humanos en el marco de la política sectorial minera, octubre 2018, p. 6 .

6 Toda la información sobre el Grupo se puede encontrar en Grupo de Trabajo sobre la cuestión de los derechos humanos y las empresas transnacionales y otras empresas, acceso el 13 de enero de 2020, https://www.ohchr.org/SP/Issues/Business/Pages/WGHRandtransnationalcorporationsandotherbusiness.aspx. 
volves various processes and has multiple objectives. The most important purpose is to prevent adverse impacts» ${ }^{7}$.

Las recientes regulaciones comunitarias sobre la publicación de la información no financiera, o las relativas a las prácticas de esclavitud moderna y deber de vigilancia se fundamentarían en estos procesos para identificar los riesgos, potenciales o reales, y para la creación de estrategias en la gestión y la minimización de los impactos. Para ello como veremos, establecen obligaciones de divulgación para las corporaciones que, debido a diferentes factores, como pueden ser su tamaño o la influencia ejercitada en el grupo, tendrían que tener un conocimiento amplio de todas las actividades empresariales desarrolladas por el grupo y que puedan tener impactos negativos sobre las comunidades locales.

De esta forma, estas normas supondrían una superación de las doctrinas clásica de personalidad jurídica separada y responsabilidad limitada de las empresas, que podría conllevar un aumento de los riesgos legales, comerciales y de reputación de las corporaciones que están obligadas a publicar la información pero que no estén tomando medidas efectivas para evaluar el riesgo, medir y reducir sus impactos en términos de derechos humanos, laborales y sobre el medio ambiente y remediar por los daños causados.

$\mathrm{Si}$ las empresas se ven obligadas y comprometidas en la transparencia de estos informes y en mantener una diligencia frente a la observancia y respeto de los derechos humanos, podría exigírseles algún tipo de responsabilidad ya sea por el incumplimiento de estos deberes, pero también por la falsedad en el contenido de los mismos. Se abriría de este modo una nueva vía de protección material de los derechos humanos si consiguiéramos articular a los afectados por estas falsedades una vía de acción jurídica vinculante para la empresa. El modo de articular esta vía será lo que exploraremos en este trabajo.

\section{La obligación de diligencia debida(reporting)}

Desde los Principios Rectores sobre empresas y derechos humanos se ha entendido la obligación de diligencia debida como un medio de identificar y mitigar los impactos de las actividades empresariales ${ }^{8}$, implicando

7 Nota al Report de 2018 (A/73/163), Corporate human rights due diligence - Background note elaborating on key aspects, Version de 16 de octubre de 2018, https://www. ohchr.org/Documents/Issues/Business/Session18/CompanionNote1DiligenceReport.pdf.

${ }^{8}$ En este sentido nos remitimos a María del Carmen Márquez Carrasco, «La implementación de los principios rectores de las Naciones Unidad sobre empresas y Derechos Humanos por medio de los planes nacionales de acción», Revista de responsabilidad social de la empresa, . $^{\circ} 20$ (2015): 55-87. 
de este modo un deber de vigilancia por el que la empresa se compromete a identificar el riesgo y evaluarlo, vigilar el desempeño en las empresas que controla o sobre las que tiene un grado elevado de control o influencia, y a dar acceso a remedios para los afectados.

El reporting, por tanto, debería reflejar toda la información relativa a estas fases de control y remedio y fomentar también un grado importante de transparencia sobre todas las precauciones «razonables» que la empresa está tomando para prevenir impactos en las comunidades donde se desarrollan sus actividades de fabricación, producción o venta de los productos. En el ámbito estatal, la obligación de debida diligencia a través del reporting está siendo incorporada en los Planes Nacionales ${ }^{9}$ así como en otras iniciativas relativas al seguimiento y vigilancia tanto de las empresas como de sus cadenas de suministro.

En el plano empresarial, los informes de sostenibilidad ${ }^{10}$, auspiciados por las normas de diligencia debida, están siendo utilizados por grandes marcas con una finalidad claramente lucrativa y de aumento de la competitividad. Sin tener que hacer necesariamente una lectura negativa de ello, lo cierto es que estas nuevas herramientas pretenden institucionalizar un modelo de negocio socialmente responsable a través de procedimientos de $r e$ porting no financiero. Hablamos de lectura negativa porque a pesar de su

${ }^{9}$ Sobre el significado y alcance de los Planes Nacionales véase https://www.businesshumanrights.org/es/herramientas-y-gu\%C3\%ADas-para-el-desarrollo-de-planes-de-acciónnacionales, así como los estudios de José Elías Esteve Moltó, «Planes de Acción Nacional sobre empresas y derechos humanos: la imperiosa complementariedad con normas vinculantes Referencia al plan español», Anuario Español de Derecho Internacional, Vol. 34 (2018): 729-751; Antoni Pigrau Solé, «El Plan de Acción Nacional de Empresas y Derechos Humanos de España. Balance y retos pendientes», PolicyPaper ICIP, n. ${ }^{\circ} 17$ (2018): 1-6; María del Carmen Márquez Carrasco, «Los planes nacionales de acción sobre empresas y derechos humanos de los estados miembros de la Unión Europea: especialmente al plan español», en $L a$ implementación de los principios rectores de las Naciones Unidas sobre empresas y derechos humanos por la Unión Europea y sus Estados Miembros, coords. por María del Carmen por Márquez Carrasco e Inmaculada Vivas-Tesón, (Pamplona: Aranzadi, 2017), 81-104; María del Carmen Márquez Carrasco, El I plan de acción nacional sobre empresas y derechos humanos de España: evaluación, seguimiento ypropuestas de revisión, (Pamplona: Aranzadi, 2019) y Humberto Cantú Rivera, «Planes de acción nacional sobre empresas y derechos humanos: sobre la instrumentalización del derecho internacional en el ámbito interno», Anuario Mexicano de Derecho Internacional, . $^{\circ} 17$ (2017): 113-144.

${ }^{10}$ Sobre los mismo véase, además de García Diez, «Información no financiera: memorias e informes de sostenibilidad», y para el contexto de los derechos humanos en concreto, a José Aureliano Martín Segura, César Pérez López y José Luis Navarro Espigares, «Los derechos humanos en las empresas multinacionales según sus informes de sostenibilidad», en Investigación e innovación en el ámbito universitario: Tendencias ante los retos actuales de la sociedad, coord. por Juan Miguel Alcántara-Pilar, M. Bermúdez Martínez, Francisco Javier Blanco Encomienda, José María Heredia Jiménez (Ed. EOS: 2017), 255-266. 
loable finalidad, en la actualidad se carece de mecanismos de sanción en caso de incumplimiento ${ }^{11}$ con las consecuencias que en buena lógica cabe extraer de esta situación para las empresas y los afectados en el sentido más amplio de la acepción ${ }^{12}$.

A pesar de ello, una lectura positiva puede mostrarnos como, frente al vacío legal internacional relativo a las responsabilidades por ilícitos internacionales, estas iniciativas están conduciendo al menos a una colaboración entre los gobiernos y los entes empresariales ${ }^{13}$, en el sentido de incorporar los avances en el tema de gestión más sostenible y la supervisión de las actividades de las empresas que participan en las cadenas de suministro, enfatizando las mejores prácticas empresariales en las diferentes dimensiones, ambiental, social y económica.

En este sentido nos asaltan varias cuestiones a resolver: ¿qué impacto están teniendo dichos informes de sostenibilidad en los mercados? Y, no menos importante, a falta de una sanción legal en caso de incumplimiento, ¿existe algún otro mecanismo que se pueda activar en los mercados para castigar a las empresas en los casos de incumplimiento?

La importancia de evaluar el impacto de los informes de sostenibilidad y planes de vigilancia es clara: en la medida que los mercados respondan o sean sensibles al contenido de los mismos, podremos medir el impacto de

11 De hecho, la crítica más frecuente es el débil régimen de sanciones en caso de incumplimiento. En la mayoría de casos el principio que se aplica es del comply or explain, en base al cual una empresa que no cumple con las reglas establecidas tendrá que motivar el porqué de tal inobservancia. En este sentido nos remitimos a Joseba Fernández Gaztea y Alberto Muñoz Fernández, «Comply or explain in the EU, orthe new human rights reporting obligation: ananalysis of directive 2014/95/EU», Cuadernos de derecho transnacional, Vol. 9, n. ${ }^{\circ} 1$ (2017): 285-299, doi: https://doi.org/10.20318/cdt.2017.3622. Como consecuencia, muchas empresas sostienen sus decisiones de no estar obligados en cumplir con una determinada norma por razones de privacy o de costes elevados. Cierto es también sin embargo, que se empieza a cambiar esta percepción y surgen posiciones que abogan por tender hacia una regulación más rigurosa, como pone de manifiesto Juan Ignacio Peinado García, «La sostenibilidad y el deber de diligencia de los administradores: Una primera reflexión sobre la sostenibilidad de la sociedad mercantil y la responsabilidad por falta de diligencia de los administradores», Revista de derecho mercantil, $\mathrm{n}{ }^{\circ} 311$ (2019): 1-30.

12 Otro dato que en este momento solo ponemos de manifiesto, es el hecho de la verificación de los datos contenidos en los informes emitidos por las Empresas. En este sentido véase el trabajo de Natalia Vaz Ogando, Silvia Ruiz Blanco y Belén Fernández-Feijóo Souto, «El mercado de verificación de las memorias de sostenibilidad en España: un análisis desde la perspectiva de la demanda», Revista de contabilidad: Spanish Accounting Review, Vol. 21, n. ${ }^{\circ} 1$ (2018):48-62, https://doi.org/10.1016/j.rcsar.2017.07.003.

13 Como puso de relieve el Informe del Department of State of the United States of America, Trafficking in Persons Report, June 2012, p. 7, https://2009-2017.state.gov/j/tip/rls/ tiprpt/2012//index.htm. 
actuar sobre ellos pudiendo así calcular los efectos expansivos a lograr, y por tanto, podremos cuantificar la mejora en términos de calidad de derechos humanos.

Previo a este cálculo, es necesario abordar el tema de las herramientas actualmente más utilizadas a escala global por las empresas para publicar su desempeño, ya que es ciertamente inútil centrarnos en el análisis de unos resultados sin ser conscientes del modo en el que se realizan los mismos o los mecanismos que intervienen en ellos. Sabedores de que los mecanismos existentes para la elaboraciónde las memorias de sostenibilidad y demás informes a los que nos referimos, no resultan del todo satisfactorios, el uso a nivel mundial del Global Reporting Initiative (GRI) ${ }^{14}$ la convierte en el instrumento de referencia a pesar de las críticas. Se ha convertido de este modo en un instrumento de apoyo a las empresas en la redacción de informes o memorias de sostenibilidad ${ }^{15}$, contribuyendo a una mayor transparencia en la gestión empresarial.

Aunque pensamos que esta herramienta presenta muchas e importantes debilidad es que podrían conducir a desconfiar de la información presentada por las empresas en lo que se refiere a la organización, estructura y desempeño de actividades en su cadena de suministro ${ }^{16}$, la inercia legislativa actual sobre diligencia debida está fomentando la utilización de los informes de sostenibilidad para fortalecer la supervisión de las empresas matrices sobre sus cadenas de suministro, por lo que se debería seguir apostando por la misma con todos los matices que podamos y queramos hacerle.

${ }^{14}$ El Global Reporting Initiative (GRI), es una organización independiente que, entre otras actividades, ayuda a las empresas a comunicar el impacto de sus actividades en temas de sostenibilidad importantes, como el cambio climático, los derechos humanos o la corrupción. Los informes se encuentran en el database de GRI que se puede consultar en https://database.globalreporting.org. Más información sobre GRI puede encontrarse en https://www.globalreporting.org/information/about-gri/Pages/default.aspx. Véase en el mismo sentido José Luis Blasco y Carlos Sáez Gallego, «Global Reporting Initiative, la historia de un éxito»,Revista de responsabilidad social de la empresa, n. ${ }^{\circ} 3$ (Ejemplar dedicado a: Empresas multinacionales y Responsabilidad Social de la Empresa) (2009): 191-201.

15 Sobre este aspecto véase Rodrigo Lozano, «Sustainability inter-linkages in reporting vindicated: a study of European companies», Journal of Cleaner Production (2013): 57-65.

${ }^{16}$ La primera y más evidente es que deja demasiada libertad a las organizaciones a la hora de proporcionar una orientación sobre cómo elaborar los informes, y esto se refleja en el grado de transparencia de las informaciones obtenidas, sobre todo en lo relativo a las categorías de impacto de desempeño social. Pero también la vaguedad de algunos de los indicadores utilizados, o la metodología empleada para determinar los aspectos materiales sobre los que informar en relación con la triple cuenta de resultados, económica, social y ambiental. 


\section{El uso del reporting en algunas normas supranacionales}

La Unión Europea también ha sido sensible a esta tendencia que apuntamos y se han seguido estas dinámicas aprobándose la Directiva 2013/34/ UE modificada por la 2014/95/UE ${ }^{17}$ sobre divulgación de información no financiera e información sobre diversidad por parte de determinadas grandes empresas y determinados grupos ${ }^{18}$, donde se establecieron pautas sobre la divulgación de información no financiera de las grandes empresas, obligando claramente a éstas a presentar un informe anual que, entre otras cosas, precisara la gestión relacionada con el respeto de los derechos humanos. El legislador comunitario, como veremos que sucede en la esfera internacional, omite mencionar los mecanismos que los Estados deberían implementar para asegurar la veracidad de la información presentada, los medios empleados por las empresas para comunicar el desempeño empresarial y los mecanismos de control y sanción que habrían de activarse en caso de incumplimiento de esta obligación.

Estas carencias se reflejan también en el ámbito interno, ya que los legisladores estatales tampoco han entrado en estos temas al implementar la Directiva. La aprobación del Real Decreto-Ley 18/2017'9 introdujo así me-

17 Respectivamente Directiva 2013/34/UE del Parlamento Europeo y del Consejo de 26 de junio de 2013, sobre los estados financieros anuales, los estados financieros consolidados y otros informes afines de ciertos tipos de empresas, por la que se modifica la Directiva 2006/43/CE del Parlamento Europeo y del Consejo y se derogan las Directivas 78/660/CEE y 83/349/CEE del Consejo, DOUE L 182, de 29 de junio de 2013, y la Directiva2014/95/UE del Parlamento Europeo y del Consejo de 22 de octubre de 2014, por la que se modifica la Directiva 2013/34/UE en lo que respecta a la divulgación de información no financiera e información sobre diversidad por parte de determinadas grandes empresas y determinados grupos, DOUE L 330, de 15 de noviembre de 2011.

${ }^{18}$ En relación con esta Directiva véase Fernández Gaztea, «Comply or explain» in the EU, or the new human rights reporting obligation: an analysis of Directive 2014/95/EU» y Mark Anthony Camilleri, «The Corporate Governance Reporting in the European Union», en Driving Productivity in Uncertain and Challenging Times, ed. por Cooper, C. (University of the West of England, 5th September). British Academy of Management, UK), https://ssrn. com/abstract $=3238662$.

19 Real-Decreto Ley 18/2017, de 24 de noviembre, por el que se modifican el Código de Comercio, el texto refundido de la Ley de Sociedades de Capital aprobado por el Real Decreto Legislativo 1/2010, de 2 de julio, y la Ley 22/2015, de 20 de julio, de Auditoría de Cuentas, en materia de información no financiera y diversidad, $B O E$ núm. 287, de 25 de noviembre de 2017. Para comprender el alcance del texto véase Carlos de Miguel Perales y Pablo Joaquín Martínez Carlos, «Información no financiera e información sobre diversidad: nuevas obligaciones», Diario La Ley, n. 9167 (2018); Ignacio Moralejo Menéndez, «Real Decreto-Ley 18/2017, de 24 de noviembre, por el que se modifican el Código de Comercio, el Texto Refundido de la Ley de Sociedades de Capital aprobado por el Real Decreto Legislativo 1/2010, de 2 de julio, y la Ley 22/2015, de 20 de julio, de Auditoría de Cuentas, en materia de información no financiera y diversidad $[B O E$ 
didas por las que las empresas obligadas debían facilitar información adecuada sobre los aspectos sobre los que existieran más probabilidades de que se materializaran los principales riesgos de efectos graves, junto con los referidos a riesgos que ya se hubieran materializado. Estos riesgos podrían derivarse de la gestión interna de la empresa o podrían estar vinculados con el desempeño de sus actividades.

En todo caso, no es descabellado acabar pensando que la normativa comunitaria no ha surtido, al estado actual, los efectos esperados. Los impactos de las actividades de las empresas europeas en el medio ambiente y los derechos humanos siguen siendo en general opacos, especialmente sobre los impactos en las cadenas de suministro globales de las empresas transnacionales. Si la información no se recopila, analiza y divulga debidamente, es difícil para las personas afectadas, como pueden ser los consumidores, comprender el alcance y el impacto de las actividades empresariales.

Junto a esto, la falta de medidas efectivas sancionatorias por parte de los Estados, ha tenido como consecuencia que solo una pequeña parte de las grandes empresas europeas informe sobre sus impactos ambientales y relativos a los derechos humanos.

No obstante, y a pesar de sus evidentes lagunas y limitaciones, este marco europeo puede sentar las bases para un nuevo modelo de informes corporativos, estandarizados, que complementen la información financiera. Y sobre todo y a los efectos que nos interesa, puede abrir nuevas vías para accionar contra violaciones de derechos humanos perpetradas por empresas, bien a partir de la propia normativa (si se consigue mayor concreción y sanciones) o bien a través de acciones impulsadas por consumidores, particulares o asociaciones, a la vista de estos informes.

En un plano supranacional, el tema del reporting acapara la mayoría de las discusiones sobre la creación de un Tratado Vinculante Sobre Empresas y Derechos Humanos (Binding Treaty) ${ }^{20}$. En junio de 2014 el Consejo

n. ${ }^{\circ}$ 287, de 25-XI-2017]», Ars Iuris Salmanticensis: AIS : revista europea e iberoamericana de pensamiento y análisis de derecho, ciencia política y criminología, Vol. $6, \mathrm{n}^{\circ} 1$ (2018): 264-269.

20 Sobre los elementos del borrador de este texto todos véanse: Adoración Guamán Hernández, «Del Documento de Elementos al Draft 0: apuntes jurídicos respecto del posible contenido del proyecto de Instrumento Vinculante sobre empresas transnacionales y otras empresas con respecto a los derechos humanos», Revista de Direito Internacional. Brazilian Journal of International Law, Vol. 15, n. ${ }^{\circ} 2$ (2018): 85-115; Adoración Guamán Hernández, «Empresas transnacionales y derechos humanos: acerca de la necesidad y la posibilidad de la adopción de un Instrumento Jurídicamente Vinculante (Binding Treaty)», Jueces para la democracia, n. 92 (2018): 100-124; Adoración Guamán Hernández, «Derechos humanos y empresas transnacionales: la necesidad de un instrumento internacional jurídicamente vinculante», Revista de derecho social, n. ${ }^{\circ} 81$ (2018): 197-218; Humberto Cantú Rivera, «¿Hacia un tratado internacional sobre la responsabili- 
de Derechos Humanos de Naciones Unidas decidió elaborar un instrumento jurídicamente vinculante sobre empresas transnacionales y otras empresas con respecto a derechos humanos ${ }^{21}$, creándose al mismo tiempo un Grupo de Trabajo Intergubernamental de Composición Abierta (Open Ended Intergovernmental Working Group, OEIGWG) estableciendo un proceso de negociaciones intergubernamentales en varias etapas ${ }^{22}$. Se iniciaba de este modo y por primera vez, un proceso intergubernamental sobre este tema en el ámbito de las Naciones Unidas, que allanaba el terreno para la adopción de un instrumento de hard law sobre la materia ${ }^{23}$.

En todo caso es necesario subrayarque de acuerdo al estado actual de las negociaciones tras cinco sesiones ${ }^{24}$, la creación de un instrumento vinculante parece destinada al fracaso ${ }^{25}$. De facto el último texto (Draft 2019)

dad de las empresas en el ámbito de los derechos humanos? Reflexiones sobre la primera sesión del Grupo de Trabajo intergubernamental de composición abierta», Anuario Mexicano de Derecho Internacional, n. ${ }^{\circ} 16$ (2016): 425-460, doi: http://dx.doi.org/10.22201/ iij.24487872e.2018.18.12106; Adoración Guamán Hernández y Gabriel Moreno González, Empresas transnacionales y derechos humanos: la necesidad de un instrumento vinculante (Albacete: Ed. Bomarzo. 2018); Adoración Guamán Hernández y Gabriel Moreno González, El fin de la impunidad: la lucha por un instrumento vinculante sobre empresas transnacionales y derecho humanos (España: Ed. Icaria, 2017), https://icariaeditorial.com/ archivo/pdf_libros/E1\%20fin\%20de\%20la\%20impunidad_descarga\%20gratuita.PDF.

${ }^{21}$ Resolución A/HRC/RES/26/9, Elaboración de un instrumento internacional jurídicamente vinculante sobre las empresas transnacionales y otras empresas con respecto a los derechos humanos, de 14 de julio de 2014.

22 Pueden consultarse los diferentes textos que han visto la luz en https://www.ohchr.org/ en/hrbodies/hrc/wgtranscorp/pages/igwgontnc.aspx.

${ }^{23}$ Sobre este tema véanse las entradas del Blog, «Law at theEnd of the Day», del Profesor Larry Catá Backer, Penn State Law University, relativas a los comentarios al Draft Treaty en: https://lcbackerblog.blogspot.com/search/label/BHR_Treaty_Draft_2019; en particular, en relación a la due diligence, el profesor Backer comenta la Declaración de la Coalición por la Paz y la Ética al inicio de la 5. a sesión del $O E I G W G$ sobre las empresas transnacionales y otras empresas con respecto a los derechos humanos, en la que se afirma (punto 5) [...] Acogemos con beneplácito los esfuerzos por introducir una regulación jurídica de la debida diligencia en materia de derechos humanos en el marco del Tratado. Pero advierte contra la naturaleza porosa del enfoque actual que producirá fractura en lugar de coherencia ya que, en sus efectos, deshará los esfuerzos para unificar la práctica de la debida diligencia de derechos humanos entre empresas y estados, independientemente de la ubicación y sin tener en cuenta las desviaciones nacionales en el país, base normativa de dicha diligencia debida. El texto en español se puede consultar en: https://lcbackerblog.blogspot.com/2019/10/declaracion-de-la-coalicion-por-la-paz.html.

${ }^{24} \mathrm{El}$ estado actual en esta Quinta Sesión puede consultarse en https://www.ohchr.org/ EN/HRBodies/HRC/WGTransCorp/Session5/Pages/Session5.aspx, al igual que el texto que actualmente se encuentra sometido a revisión: https:/www.ohchr.org/Documents/HRBodies/ HRCouncil/WGTransCorp/Session5/IGWG_5th_DraftReport.docx.

${ }^{25}$ Desde la cuarta reunión en Ginebra sobre esta materia, muchos países han rechazado abiertamente la creación de una nueva norma, como ya habían hecho la Unión Europea y los Estados Unidos, lo que dificultará claramente el debate internacional sobre esta materia. 
ni crea herramientas nuevas para enfrentarse a la impunidad de las corporaciones, ni incorpora mecanismos de responsabilidad legal de las empresas (en general o en particular)sobre las cadenas de suministros. A pesar de ello, seguimos creyendo que esta sería la vía más oportuna y adecuada para evitar que la responsabilidad de las grandes empresas transnacionales se viera afectada por la inexistente regulación a nivel internacional, o por la debilidad en materia de protección de los derechos humanos de las legislaciones nacionales en un plano más interno.

En todo caso, y volviendo al tema de la due diligence, el art. 5 apartados 2 y 3 del Draft 2019 como antes lo hiciera el art. 9 del Draft 2018 (Tabla 1) señalan una serie de obligaciones (elenco no cerrado y susceptible de ser ampliado), pero de nuevo no se crean mecanismos de sanción en caso de incumplimiento. Y en todo caso, y aunque consten una serie de obligaciones, las mismas no garantizan por sí solas el acceso a los tribunales de las víctimas u otros afectados de las graves violaciones perpetradas por empresas fuera de sus países de origen. Reproducimos en la Tabla 1 una lectura comparativa del texto de los documentos del año 2018 y 2019 para visualizar la tendencia legislativa a la que nos referimos ${ }^{26}$ :

\section{Tabla 1}

\begin{tabular}{l|l}
\hline \multicolumn{1}{c|}{ Article 5. Prevention. Draft 2019 } & \multicolumn{1}{c}{ Article 9. Prevention. Draft 2018 } \\
\hline $\begin{array}{l}\text { 2. For the purpose of paragraph 1 of this } \\
\text { Article, State Parties shall adopt meas- } \\
\text { ures necessary to ensure that all persons }\end{array}$ & $\begin{array}{l}\text { 2. Due diligence referred to above under } \\
\text { Article 7.1 shall include, but shall not be } \\
\text { necessarily limited to: }\end{array}$ \\
$\begin{array}{l}\text { conducting business activities, including } \\
\text { those of transnational character, to under- } \\
\text { take human rights due diligence as fol- } \\
\text { lows: }\end{array}$ & \\
\hline $\begin{array}{l}\text { a. Identify and assess any actual or po- } \\
\text { tential human rights violations or abuses } \\
\text { that may arise from their own business } \\
\text { activities, or from their contractual rela- } \\
\text { tionships; }\end{array}$ & $\begin{array}{l}\text { its business activities including the activi- } \\
\text { ties its subsidiaries and that of entities } \\
\text { under its direct or indirect control or di- } \\
\text { rectly linked to its operations, products } \\
\text { or services. }\end{array}$ \\
\hline
\end{tabular}

${ }^{26}$ La cursiva es nuestra. 


\begin{tabular}{l} 
Article 5. Prevention. Draft 2019 \\
\hline b. Take appropriate actions to prevent \\
human rights violations or abuses in the \\
context of its business activities, includ- \\
ing those under their contractual rela- \\
tionships;
\end{tabular}

c. Monitor the human rights impact of their business activities, including those under their contractual relationships;
Article 9. Prevention. Draft 2018

b. Identify and assess any actual or potential human rights violations that may arise through their own activities including that of their subsidiaries and of entities under their direct or indirect control or directly linked to its operations, products or services.

c. Prevent human rights violations within the context of its business activities, including the activities of its subsidiaries and that of entities under its direct or indirect control or directly linked to its operations, products or services, including through financial contribution where needed.

d. Reporting publicly and periodically on non-financial matters, including at a minimum environmental and human rights matters, including policies, risks, outcomes and indicators. The requirement to disclose this information should be subject to an assessment of the severity of thepotential impacts on the individuals and communities concerned, not to a consideration of their materiality to the financial interests of the business or its shareholders.

e. Undertaking pre and post environmental and human rights impact assessments covering its activities and that of its subsidiaries and entities under its control, and integrating the findings across relevant internal functions and processes and taking appropriate action.

a. Undertaking environmental and human rights impact assessments in relation to its activities and those under their contractual relationships, integrating the results of such assessments into relevant internal functions and processes, and taking appropriate actions. f. Reflecting the requirements in paragraphs a. to e. above in all contractual relationships which involve business activities of transnational character. 


\begin{tabular}{|c|c|}
\hline Article 5. Prevention. Draft 2019 & Article 9. Prevention. Draft 2018 \\
\hline $\begin{array}{l}\text { b. Carrying out meaningful consultations } \\
\text { with groups whose human rights can po- } \\
\text { tentially be affected by the business ac- } \\
\text { tivities, and with other relevant stake- } \\
\text { holders, through appropriate procedures } \\
\text { including through their representative in- } \\
\text { stitutions, while giving special attention } \\
\text { to those facing heightened risks of viola- } \\
\text { tions of human rights within the context } \\
\text { of business activities, such as women, } \\
\text { children, persons with disabilities, indig- } \\
\text { enous peoples, migrants, refugees, in- } \\
\text { ternally displaced persons and protected } \\
\text { populations under occupation or conflict } \\
\text { areas. Consultations with indigenous peo- } \\
\text { ples will be undertaken in accordance } \\
\text { with the internationally agreed standards } \\
\text { of free, prior and informed consultations, } \\
\text { as applicable. }\end{array}$ & $\begin{array}{l}\text { g. Carrying out meaningful consulta- } \\
\text { tions with groups whose human rights are } \\
\text { potentially affected by the business ac- } \\
\text { tivities and other relevant stakeholders, } \\
\text { through appropriate procedures including } \\
\text { through their representative institutions, } \\
\text { while giving special attention to those } \\
\text { facing heightened risks of violations of } \\
\text { human rights within the context of busi- } \\
\text { ness activities, such as women, children, } \\
\text { persons with disabilities, indigenous peo- } \\
\text { ples, migrants, refugees and internal dis- } \\
\text { placed persons. }\end{array}$ \\
\hline $\begin{array}{l}\text { c. Reporting publicly and periodically on } \\
\text { financial and non-financial matters, in- } \\
\text { cluding policies, risks, outcomes and in- } \\
\text { dicators on human rights, environment } \\
\text { and labour standards concerning the con- } \\
\text { duct of their business activities, including } \\
\text { those of their contractual relationships. }\end{array}$ & $\begin{array}{l}\text { h. Due diligence may require establish- } \\
\text { ing and maintaining financial security, } \\
\text { such as insurance bonds or other financial } \\
\text { guarantees to cover potential claims of } \\
\text { compensation. }\end{array}$ \\
\hline $\begin{array}{l}\text { d. Integrating human rights due diligence } \\
\text { requirements in contractual relationships } \\
\text { which involve business activities of a } \\
\text { transnational character, including through } \\
\text { financial contributions where needed. }\end{array}$ & \\
\hline $\begin{array}{l}\text { e. Adopting and implementing enhanced } \\
\text { human rights due diligence measures to } \\
\text { prevent human rights violations or abuses } \\
\text { in occupied or conflict-affected areas, } \\
\text { arising from business activities, or from } \\
\text { contractual relationships, including with } \\
\text { respect to their products and services. }\end{array}$ & \\
\hline
\end{tabular}

Fuente: elaboración propia. 
Una simple lectura preliminar, pone en evidencia (en el texto resaltado en cursiva) que en la nueva versión se registra un retroceso en relación a la problemática de determinar qué entidades empresariales se entienden comprendidas dentro de la obligación de reporting de la empresa matriz. Para contestar a esta pregunta el Draft 2018 indicaba claramente que debían entenderse las subsidiarias y las otras entidades conectadas directamente o indirectamente con sus actividades económicas de la empresa matriz; esto es, para conectar estas empresas con la matriz, utilizaba el concepto de control directo o indirecto. Pero en el actual Draft 2019 se usa un lenguaje poco claro, «that may arise from their activities, or from those under their contractual relationships», y no coherente con las normas nacionales actualmente existentes sobre la debida diligencia de derechos humanos.

Todo ello nos inclina a pensar que en el nuevo borrador no se está avanzando en la creación de mecanismos para hacer respetar y cumplir a las empresas estas obligaciones, ni se articulan foros para las víctimas o para otros grupos de afectados de ilícitos internacionales. Establecen todo lo más la obligación del Estado de velar por el desempeño empresarial de las entidades que estén en su territorio o bajo su jurisdicción, y que desarrollen actividades de carácter transnacional, animándolas a que aseguren procedimientos nacionales efectivos para hacer cumplir estas obligaciones y determinar las responsabilidades e indemnizaciones correspondientes. Y esto lo promueven haciendo hincapié en estos casos en una de las obligaciones de debida diligencia: el reporting no financiero (art. 5.3.c. Draft 2019 y art.9.2.d. Draft 2018).

En todo caso, es constatable la creciente vaguedad con la que cada modificación del Draft afronta el tema de las medidas específicas que los Estados deberían implementar para controlar la veracidad de la información no financiera presentada, y sancionar en su caso la información fraudulenta. En el mismo sentido la identificación de los mecanismos que las empresas deberían utilizar para su comunicación, dejándolas libres de elegir el medio utilizado sin superar los obstáculos antes mencionados relativos a lo vago de los indicadores sobre el desempeño empresarial en temas sociales y medioambientales.

Queremos hacer una lectura interesada, en el sentido de que resulta paradójico que por un lado las empresas constaten y utilicen estos informes para mejorar su marca y su imagen, pero al mismo tiempo huyan de cualquier responsabilidad por el contenido de estos informes. ¿No sería posible suponer que si las empresas hacen uso continuo de estos informes, certificados etc...podríamos utilizar los mismos para exigir responsabilidades en el caso de que existiera falsedad en su contenido? 


\section{La utilización del reporting en un plano nacional}

El Estado de California fue pionero en introducir esta herramienta como obligación de diligencia debida, creando una Ley de California sobre Transparencia en la Cadena de Suministros (CTSC) ${ }^{27}$ que establecía sanciones a las empresas exclusivamente por el incumplimiento de la publicación de información empresarial, sin entrar a valorar el contenido de la información difundida. Con esta norma no se buscaba tanto un medio para obtener reparación por los daños causados, sino prevenir que éstos se produjeran mediante la obligación de divulgar las acciones en favor de la erradicación de las violaciones de derechos humanos llevadas a cabo, no sólo dentro de la propia empresa, sino también en su cadena de suministro. La CTSC se apoyaba en la confianza de que el consumidor premiaría o castigaría a aquellas empresas que realizaran actividades comerciales, en función de la preocupación de éstas por el respeto de los derechos humanos en su cadena de suministro.

Desde que entró en vigor el 1 de enero de 2012, y al margen de otras valoraciones, supuso al menos la obligación de publicar los esfuerzos por controlar que quienes formaban parte de la cadena de suministro de estas grandes corporaciones no incurrían en trata de personas ni en prácticas esclavistas. Sin embargo, y aunque la CTSC ha hecho que numerosas empresas estén cumpliendo con el mandato impuesto de información, lo cierto es que su impacto no ha sido del calado que esperaban algunos sectores $^{28}$. También es cierto que si atendemos a las resoluciones judiciales surgidas a consecuencia de esta ley, hemos de constatar algún avance en la materia como ilustra el caso Barber v. Nestlé USA Inc..$^{29}$, aunque ciertamente tal caso alerta asimismo sobre la paradoja que encierra esta norma: la ley no fue invocada por los demandantes (consumidores), sino por Nestlé, que encontró en la CTSC un puerto seguro y asidero legal frente

27 Senate Bill Núm. 657. CHAPTER 556. An act to add Section 1714.43 to the Civil Code, and to add Section 19547.5 to the Revenue and Taxation Code, relating to human trafficking (California Transparency in Supply Chains Act). El texto completo de la ley se puede consultar en http://www.leginfo.ca.gov/pub/09-10/bill/sen/sb_0651-0700/sb_657_ bill_20100930_chaptered.pdf.

${ }^{28}$ Según el informe de 2017 elaborado por Development International, que puede consultarse en https://www.ipoint-systems.com/fileadmin/media/resources/CA-TISCA.v.25_S. pdf.

${ }^{29}$ Barber v. Nestle USA, Inc., 154 F. Supp. 3d 954 (C.D. Cal.), resuelto el 9 de diciembre de 2015. Sobre este asunto véase Alberto Muñoz Fernández y Lorena Sales Pallarés, «Las leyes anti esclavitud: primeras respuestas judiciales», en Empresas y derechos humanos: temas actuales, coords. por María Chiara Marullo y Francisco Javier Zamora Cabot (Napoli: EditorialeScientifica, 2018), 277-303. 
a este tipo de demandas. En este sentido, creemos importante destacar las consecuencias que estas iniciativas están teniendo en la implementación de informes para la evaluación de la sostenibilidad empresarial, sin dejar de un lado la preocupación frente a la posibilidad de que estas normas se conviertan en puertos seguros para las empresas para escaparse de sus responsabilidades por los ilícitos perpetrados extraterritorialmente por sus cadenas de suministro.

En todo caso, la iniciativa californiana hace palpable el auge de la preocupación por la protección de los derechos humanos en relación con las empresas, especialmente en la vertiente de la esclavitud moderna y la vinculación con la responsabilidad empresarial,plasmándose en el desarrollo nacional de legislaciones similares desde entonces, que van desde la $U K$ Modern Slaver yAct of $2015^{30}$ o la French Duty of Vigilance Law $2017^{31}$, a iniciativas como la German Legislative Proposal: Corporate Responsibility and Human Rights ${ }^{32}$; la Canada's Modern Slavery Act, an Act respecting the fight against certain forms of modern slavery through the imposition of certain measures and amending the Customs Tariff33; la Australian Commonwealth Modern Slavery Act ${ }^{34}$, o la Modern Slavery Bill to criminalize all forms of human trafficking in Hong Kong ${ }^{35}$.

El Gobierno canadiense ha anunciado también la intención de crear un Independent Canadian Ombudsperson for Responsible Enterprise,

30 Disponible en:http://www.legislation.gov.uk/ukpga/2015/30/contents/enacted.

31 Disponible en: https://www.legifrance.gouv.fr/affichTexte.do?cidTexte=JORFTEXT0 $00034290626 \&$ dateTexte $=20190724$.

32 Disponible en: https://germanwatch.org/sites/germanwatch.org/files/publication/18575.pdf.

${ }^{33}$ Disponible en:https://www.parl.ca/DocumentViewer/en/42-1/bill/C-423/first-reading. Se establece en ella que estarán obligadas a proporcionar la información relativa a las prácticas de esclavitud las empresas o sociedades canadienses que coticen en una bolsa de valores canadiense o que tengan una sede en Canadá, negocios en Canadá o tengan activos en Canadá y cumplan al menos dos de las siguientes condiciones: (a) tiene al menos $\mathrm{C} \$ 20$ millones en activos, (b) ha generado al menos \$40 millones en ingresos o (c) emplea un promedio de al menos 250 empleados.

Estos entes estarían obligados a discutir: 1. Los pasos tomados durante el año anterior para prevenir y reducir el riesgo de trabajo forzado o infantil en cualquier etapa de la fabricación, producción, cultivo, extracción o procesamiento de bienes en Canadá importados a Canadá; 2. la estructura y mapa de los suppliers; 3 . las políticas y estrategias de la empresa matriz; 4. las actividades de las empresas que pertenecen al grupo y que conllevan un riesgo elevado y los pasos que ha tomado para evaluar y gestionar ese riesgo; 5 . cualquier medida tomada para remediar los impactos negativos.

34 Disponible en: https://www.aph.gov.au/Parliamentary_Business/Bills_Legislation/ Bills_Search_Results/Result?bId=r6148.

${ }_{35}$ Disponible en: https://www.legco.gov.hk/yr17-18/english/panels/se/agenda/ se20180605.htm. 
para garantizar la protección de los derechos humanos y responsabilizar a las empresas canadienses por sus actividades delictivas extraterritoriales ${ }^{36}$, así como proponer la modificación de la Customs Tariff para prohibir la importación de bienes fabricados o producidos por trabajo forzado o infantil ${ }^{37}$.

La referencia genérica a las empresas se afina atendiendo a los diferentes ámbitos de aplicación de las normas a las que nos hemos referido, en el sentido de atender bien al tamaño bien al grado de influencia que ejercen o a su facturación. Así, la UK Modern Slavery Act of 2015 por ejemplo, centra la atención en la facturación anual de las empresas para determinar las empresas nacionales sujetas a esta norma, que quedan de este modo obligadas a informar sobre su cadena de suministro. En los mismos términos se presenta la propuesta australiana (Australian Commonwealth Modern Slavery Act), mientras que en Francia, con la French Duty of Vigilance Law 2017, el requisito para determinar la obligación se extiende al número de empleados que tiene la empresa francesa, de modo que superado un determinado número estará sujeta a esta obligación de reporting.

También resulta interesante la Swiss Responsible Business Iniciative ${ }^{38}$ según la cual, para determinar las empresas que estarían sujetas a esta obligación de diligencia debida, se buscan cumulativamente el criterio del tamaño y de los riesgos que conllevan sus actividades extraterritoriales, dependiendo del sector en el que actúan ${ }^{39}$.

${ }^{36}$ El mandato de este nuevo órgano es: «The Ombudsperson's mandate is to address complaints related to allegations of human rights abuses arising from a Canadian company's activity abroad. The Ombudsperson is mandated to undertake collaborative and independent fact-finding, make recommendations, monitor implementation of those recommendations, and report publicly throughout the process.The mandate and associated responsibilities are outlined through an Order in Council (2019-1323)». Para más información: https://www.international.gc.ca/trade-agreements-accords-commerciaux/topics-domaines/other-autre/faq. aspx?lang=eng.

37 Sobre este tema: https://www.ropesgray.com/en/newsroom/alerts/2019/04/ModernSlavery-Compliance-For-US-based-and-Other-Multinationals-A-Review-of-Recent-Compliance-

38 Véase http://www.bhrinlaw.org/key-developments/64-switzerland.

39 Nicolás Bueno, The Swiss Responsible Business Initiative and its Counter-Proposal: Texts and Current Developments, https://www.academia.edu/38507525/The_Swiss_Responsible_Business_Initiative_and_its_Counter-Proposal_Texts_and_Current_Developments; Nicolás Bueno, The Swiss Popular Initiative on Responsible Business. From Responsibility to Liability, https://papers.ssrn.com/sol3/papers.cfm?abstract_id=3125672; Valentin Jentsch, «Corporate Social Responsibility and the Law: International Standards, Regulatory Theory and the Swiss Responsible Business Initiative», EUI Working Papers MWP 2018/05, http://diana-n.iue.it:8080/bitstream/handle/1814/59084/MWP_WP_Jentsch_2018_05. pdf? sequence $=1 \&$ isAllowed $=y$. 
Más en línea con la norma californiana, el interés protegido en la Dutch Child Labor Due Diligence Act $t^{40}$ parece ser el de un consumidor informado. En este sentido la norma holandesa va un paso más allá ya que a diferencia del resto de normas señaladas, en lo referente a la sanción plantea que si las autoridades determinan que la empresa no ha llevado a cabo la debida diligencia de acuerdo con la legislación, se le proporcionan a la empresa instrucciones jurídicamente vinculantes y un plazo para su ejecución. El texto de la nueva regulación tendrá en cuenta la herramienta y los indicadores creados por la OIT sobre trabajo infantil ${ }^{41}$, para definir cómo las empresas deben evaluar sus riesgos. Si no se cumplen las obligaciones establecidas en la norma, la empresa puede ser multada, y si es multada dos veces en un plazo de cinco años, la siguiente violación puede llevar al encarcelamiento del director responsable. Víctimas, consumidores y otros stakeholders podrán presentar una queja relativa al incumplimiento. En el caso más extremo, el incumplimiento de la ley puede dar lugar a penas de prisión y multas de 750.000 euros o del $10 \%$ del volumen de negocios anual de la empresa $^{42}$.

Sobre las sanciones por incumplimiento de estas leyes, y a salvo de lo dicho sobre la holandesa, la mayoría de veces estas se encuentran directamente relacionadas con la naturaleza y los fines perseguidos por los legisladores, esto es, son leyes de divulgación y, por ello, las sanciones no son ni numerosas, ni están dirigidas a compensar a las víctimas por los daños sufridos.

Frente a ello, somos de la opinión de que el mecanismo de reporting debería estar acompañado de un sistema de sanciones tendentes a desincentivar prácticas fraudulentas en la información proporcionada por las empresas y contemplar la posibilidad de que las acciones sancionatorias puedan ser activadas también por las denuncias de asociación de consumidores, usuarios u otros afectados.

Hemos enunciado solamente algunos ejemplos de legislaciones nacionales o propuestas que fomentan la transparencia en los procesos de gestión de las cadenas de suministro y que se apoyan en el reporting de algún modo para prevenir y minimizar los impactos de las actividades empresariales fuera de sus países de origen. No es la solución pero si es un buen co-

40 Véase https://www.mvoplatform.nl/en/the-netherlands-takes-a-historic-step-by-adopting-child-labour-due-diligence-law/.

41 Más información sobre la herramienta de la OIT, acceso el 13 de enero de 2020,https://www.ilo.org/ipec/Informationresources/WCMS_IPEC_PUB_27555/lang--en/index.htm.

42 Más información en https://www.mvoplatform.nl/en/frequently-asked-questionsabout-the-new-dutch-child-labour-due-diligence-law/. 
mienzo del que asirse en la mejora de los derechos humanos en su relación con las empresas.

\section{Abriendo nuevos caminos desde reflexiones críticas sobre lo existente y lo venidero}

Somos conscientes de que una nueva política empresarial más sostenible en términos sociales necesita tiempo para ser implementada y que los resultados que hasta este momento tenemos son parciales y hasta cierto punto poco representativos. No obstante, parece oportuno hacer algunas críticas constructivas antes de proponer nuevos caminos ya que, conforme a los estudios sectoriales y estatales, los resultados obtenidos a través de esta divulgación no son prometedores ${ }^{43}$.

Cuando el Gobierno del Reino Unido introdujo la primera regulación en materia de esclavitud en Europa con su UK Modern Slavery Act of 2015, se afirmó que la legislación tenía como objetivo sentar las bases para una política de transparencia en actividades de las multinacionales y de sus cadenas de suministro globales ${ }^{44}$. La ley requería de las corporaciones, con sede en el Reino Unido que tuvieran una determinada facturación, que presentaran una declaración anual relativa a las prácticas de esclavitud moderna y tráfico de personas. Del análisis de estas declaraciones durante estos años, si bien se puede evaluar positivamente el hecho de que las empresas estén dispuestas a mejorar su desempeño en términos sociales, conforme a los requisitos legales nacionales y los estándares básicos internacionales, la información pública proporcionada refleja casi siempre los resultados positivos obtenidos y sirve, en muchos casos, como escaparate para mostrar a los consumidores y a los otros stakeholders las «buenas prácticas» puesta en marcha por la empresa que controla o tiene influencia en el grupo, pero se omiten las actividades de las filiales o de otras empre-

${ }^{43}$ En este sentido véase Leona Vaughn, Alex Balch, Jennifer Johns, \& Samantha Currie, «Transparency in Supply Chains and the Lived Experiences of Workers and Their Families in the Garment Sectors of Bangladesh And Myanmar», Journal of the British Academy, Vol. 7, S1 (2019): 35-60, https://www.thebritishacademy.ac.uk/publications/journal-britishacademy/7s $1 /$ transparency-in-supply-chains-and-experiences-of-workers-in-garment-sectors; Hinrich Voss, Matthew Davis, Mark Sumner, Louise Waite, Ilse A. Ras, Divya Singhal y Deepti Jog, «International Supply Chains: Compliance and Engagement with the Modern Slavery Act», Journal of the British Academy, Vol. 7, S1 (2019): 61-76, https://www thebritishacademy.ac.uk/publications/journal-british-academy/7s1/international-supply-chains-compliance-and-engagement-modern-slavery-act.

44 Agnes Simicy Brad K. Blitz, «The modern slavery regime: a critical evaluation», Journal of the British Academy, 7, S1 (2019):1-34. 
sas controladas por la empresa matriz o principal $^{45}$ que sí cuentan con un alto grado de riesgos en términos sociales o laborales ${ }^{46}$.

A UK registry of statements shows that over 750 companies-the majority of which are headquartered in either the UK or the US-have now published statements. While the legal requirements themselves do not obligate businesses to produce extensive statements or reports, current market practice strongly suggests that businesses across a variety of industries-including manufacturing, energy, technology, pharmaceutical, utilities, food and drug, consumer products, and professional services-are doing more than is strictly necessary to comply with the regulations. Unsurprisingly, few (if any) statements indicate that no steps have been taken, though such a statement would satisfy the requirements ${ }^{47}$.

Hasta la fecha, la implementación de la Ley francesa no ha tenido mejores resultados ${ }^{48}$. Esta norma establece obligaciones para las empresas matrices francesas, en el sentido de que deberán identificar y prevenir los impactos negativos en los derechos humanos, la salud y el medioambiente resultantes de sus actividades y las de las empresas que controlan, tanto sean subcontratistas como proveedoras ${ }^{49}$. Las empresas sujetas a esta

45 En mayo de 2019 se publicó el Independent Review of the Modern Slavery Act 2015: Final Report, que ha tenido como objetivo investigar la efectividad de la Ley inglesa y sugerir posibles mejoras. En el mismo los autores evidencian el potencial de esta regulación, pero al mismo tiempo denuncian las graves deficiencias que se dan ya que la norma deja a las corporaciones una flexibilidad demasiado amplia sobre los datos que debe publicar relativos a su desempeño en términos sociales. El informe está disponible en: https://assets.publishing.service.gov.uk/government/uploads/system/uploads/attachment_data/file/803406/Independent_ review_of_the_Modern_Slavery_Act_-_final_report.pdf.

${ }^{46}$ Lisa Rende Taylor y Elena Shih, «Worker Feedback Technologies and Combatting Modern Slavery in Global Supply Chains: Examining the Effectiveness of Remediation-oriented and Due-diligence-oriented Technologies in Identifying and Addressing Forced Labour and Human Trafficking», Journal of the British Academy, 7, S1 (2019): 131-165.

47 Más información en: https://www.globalpolicywatch.com/2016/10/uk-rules-prompt-businesses-to-report-on-slavery-in-their-supply-chains/?_ga=2.17912505.1011687002.1568754636560531109.1511261728

${ }^{48}$ Sobre los primeros resultados de la aplicación de esta ley véase Pierre Lequet, «Loi «devoir de vigilance»: de l'intérêt des nomes de management des risques», Revue juridique de l'environnement, . $^{\circ}$ 4(2017): 705-725. Es interesante también ver el informe elaborado por Charlotte Michon, Sophie Berne y Sylvain Boucherand, «Application of the law on the corporateduty of vigilance analysis of the first published plans», en https://www.e-dh.org/ userfiles/Edh_2018_Etude_EN_1.pdf.

49 Pueden consultarse las empresas cubiertas por esta ley desde https://vigilance-plan. org/ así como puede consultarse el estudio realizado por Charlotte Michon y Julia Velho, Application of the Law in the Duty of Vigilance. Vigilance plans 2018-2019, June 14, 2019 
norma, entre otras medidas, deberán así establecer y aplicar efectivamente un plan de vigilancia que cubra las actividades de la empresa matriz y de las demás empresas bajo su control, así como de los proveedores y subcontratistas con los que la empresa matriz o cualquiera de sus filiales establezcan una relación comercial.

Como hemos mencionado, lo que se establece es la obligación de la empresa domiciliada en Francia, que en muchos casos es la matriz del grupo, y que por tanto es la que coordina o controla al grupo de empresas, filiales, proveedores y subcontratistas, las obliga decíamos a publicar, a través de un plan de vigilancia, la estructura del grupo, sus mapas de riesgos, las estrategias, etc., en relación a los riegos y los mecanismos para reducir los impactos y dar seguimiento de las medidas y de su eficacia ${ }^{50}$. En un primer momento, esta obligación estuvo acompañada de la posibilidad de imponer multas por el incumplimiento del plan de vigilancia, pero estas disposiciones fueron declaradas inconstitucionales ${ }^{51}$.

Sinceramente y visto lo expuesto hasta ahora, la vulneración de los derechos humanos por parte de las multinacionales no se ha conseguido ni frenar ni sancionar, a pesar de los diferentes intentos legislativos que hasta este momento se han intentado, o lo han hecho de un modo demasiado tibio $^{52}$. Hay por tanto que abrir nuevos caminos, sintetizados en tres grandes vías de acción a nuestro entender: bien buscar la responsabilidad indirecta de la matriz por las violaciones de los derechos humanos perpetradas por sus filiales ${ }^{53}$; bien forzar una acción por competencia desleal por parte de otras empresas que se verían perjudicadas por falsear el mercado a través de los informes de sostenibilidad emitidos por empresas competidoras en

Edition, https://www.e-dh.org/userfiles/Etude\%20plans\%20de\%20vigilance\%202019\%20 -\%20VEN.pdf.

50 Véase Antonia Durán Ayago, «Sobre la responsabilidad de las empresas por violaciones graves de los derechos humanos en terceros países (a propósito de la Ley francesa 2017 399, de 27 marzo 2017, relativa al deber de vigilancia de las empresas matrices sobre sus filiales)», Anuario Español de Derecho internacional privado, Tomo XVIII (2018): 323-348; y Guamán Hernández, «Diligencia debida en derechos humanos y empresas transnacionales: de la ley francesa a un instrumento internacional jurídicamente vinculante sobre empresas y derechos humanos», 246.

${ }^{51}$ Conseil constitutionnel n. ${ }^{\circ}$ 2017-750 DC de 23 marzo 2017. Más información en: https://www.conseil-constitutionnel.fr/decision/2017/2017750DC.htm.

${ }^{52}$ El centro Human Rights International Corner - ETS (https://www.humanrightsic. com/home-eng) está desarrollando estudios sobre la Ley de Diligencia debida y en este sentido destaca por su interés el Report, Italian Legislative Decree $N^{\circ}{ }^{\circ}$ 231/2001: A model for Mandatory Human Rights Due Diligence Legislation?, en https://e6e968f2-1ede-4808-acd7cc626067cbc4.filesusr.com/ugd/6c779a_d800c52c15444d74a4ee398a3472f64c.pdf.

53 En el mismo sentido James Sinclair, «Strategic Litigation as a Tool to Combat Modern Slavery», Journal of Modern Slavery, Vol. 4, n. 2 (2018): 49. 
su mercado ${ }^{54}$; o bien fomentando reclamaciones o acciones por parte de los consumidores ${ }^{55}$.

La primera de las posibilidades parte de la premisa de que las normas al establecer el grado de diligencia exigible a las empresas lo hacen en función de diferentes factores, como el tamaño, la facturación o el sector de sus actividades económicas, de modo que no hacen sino reconocer implícitamente la condición de liderazgo que ostentan y con ello su influencia, control o dominio sobre las demás. De esta forma, no se puede negar que las empresas que están obligadas a publicar los informes, planes de vigilancia u otros documentos relativos a la información no financiera, también tienen capacidad de influenciar sobre las demás empresas que pertenecen al grupo hasta tener, en algunos casos, un control total o un dominio sobre ellas. Influencia significa, o debería significar, disponer de un poder, que va más allá del poder económico que conlleva la capacidad de determinar las estrategias empresariales del grupo y tomar las decisiones más relevantes sobre las actividades. Significa también entender que se estaría reconociendo, siquiera implícitamente, la conexión existente entre ellas, y la posición de superioridad jerárquica ejercitada por la empresa sobre la que grava la obligación de reporting, la empresa matriz, y las otras empresas pertenecientes al grupo. Si esto es así, la esencia de la obligación que se pretende exigir a las empresas es por tanto la prevención y la vigilancia hacia sus propias actividades y hacia las empresas filiales sobre las que ejercen este control, así como las empresas proveedoras o subcontratadas con las que mantienen relaciones comerciales y sobre las que tienen influencia, y no solamente la mera publicación de la información ${ }^{56}$.

${ }^{54}$ El planteamiento de esta vía forma parte de una línea de investigación abierta recientemente, que parte de entender que cuando los informes de sostenibilidad, incluso en algunos casos también de los certificados, son falseados de modo directo o indirecto por parte de la empresa, eso provoca una alteración «fraudulenta» del flujo del mercado, de modo que podría entenderse como una práctica de competencia desleal entre empresas. Si pudiera interpretarse como una acción de competencia desleal (dentro de las diferentes normas que la regulan básicamente a nivel nacional pero también comunitario) esto debería dar derecho a plantear acciones judiciales entre empresas, y por tanto actuar de un modo mucho más directo y tal vez efectivo en los mercados y las empresas.

55 Bien es cierto que hasta el mismo concepto de consumidor está siendo reinterpretado y actualizado como lo demuestra la STJUE Sentencia del Tribunal De Justicia (Sala Primera) de 3 de octubre de 2019, Asunto C-208/18, Jana Petruchová contra FIBO Group Holdings Limited, (http://curia.europa.eu/juris/document/document.jsf;jsessionid=55B9E7D96FCCFD0A 8729326AC30D6594?text $=\&$ docid $=218626 \&$ pageIndex $=0 \&$ doclang $=E S \&$ mode $=1$ st $\&$ dir $=\&$ occ=first \&part=1\&cid=717523, y habrá que atender cuidadosamente al alcance de esta «Doctrina Petruchová».

56 Algunos asuntos ya han sido juzgados en tribunales ingleses atendiendo a esta interpretación extensa del levantamiento del levo, así Lungawe and others $v$. Vedanta Resources 
Ello podría implicar, o al menos haría factible interpretar, un concepto unitario de grupo de empresas donde la matriz fuera la empresa que controla el grupo, estableciendo las estrategias y tomando las decisiones relativas a las actividades empresariales. Por tanto, esta última tiene una responsabilidad indirecta, si no ha activado debidamente medidas preventivas adecuadas para prevenir los daños, sobre las actividades desarrolladas extraterritorialmente por las otras empresas, siempre que no se demostrara que no tiene control sobre las mismas, invirtiendo de esta forma la carga de la prueba. Plantearíamos por tanto una responsabilidad indirecta solidaria con la empresa local en casos de graves violaciones a los derechos humanos.

Por ello, creemos que los informes de sostenibilidad y los planes de vigilancia posibilitarían demandar a las empresas matrices cuando se demostrara que bien no han cumplido con la obligación genérica de publicar el mapa de las empresas que pertenecen al grupo, los riesgos y las medidas adoptadas para reducir los impactos, según los requerimientos de cada legislación estatal, pero también deberían servir para entablar una relación entre la empresa matriz y sus filiales ${ }^{57}$, cuando se desprendiera que la existencia de una conexión real entre ambas, cuando estas últimas estuvieran bajo su control y dominio, responsabilizando a la matriz por los delitos extraterritoriales por no haber activado las medidas concretas para controlar las actividades extraterritoriales y mitigar los impactos negativos.

Al mismo tiempo, podríamos avanzar en la dirección de que estos informes activaran la competencia del foro del domicilio de la empresa matriz, donde la empresa está obligada a publicar sus informes o documentos de sostenibilidad, para entablar demandas sobre daños extraterritoriales. En otras palabras, si las empresas que pertenecen al grupo de la matriz causan un daño fuera del Estado del foro y se logra relacionar este daño con el deber de vigilancia, debería ser posible utilizar el foro de la empresa matriz para exigir su responsabilidad solidariacon la filial, rompiendo, de esta forma, las reglas de la responsabilidad jurídica limitada y personalidad jurídica separada.

En esta línea, en octubre de 2019,seisONGs han demandado en Francia a la empresa Total por incumplir su deber de vigilancia sobre sus filiales, involucradas en Uganda en graves violaciones de los derechos humanos y del medio ambiente.

PLC and Konkola Copper Mines PLC ([2017] EWCA Civ. 1528) o Okpabi and others v Royal Dutch Shell ([2017] EWHC 89).

57 No sería necesario recurrir a la doctrina clásica del levantamiento del velo aunque podríamos utilizarlo cual «test de efectos» para reafirmar la relación de dependencia entre las empresas a las que nos estuviéramos refiriendo. 
La multinacional petrolera francesa Total es el principal operador del mega proyecto petrolero Tilenga, junto con la firma británica Tullow Oil y la China National Offshore Oil Corporation (CNOOC), que planea perforar más de 400 pozos en seis campos petroleros y construir un oleoducto de 900 millas hasta Tanzania, lo que conllevará el desplazamiento de unos 50.000 agricultores en las regiones occidental y central de Uganda. Según los abogados de las OGNs, la ley francesa obligaría a Total a publicar los verdaderos impactos negativos de sus actividades petroleras, operadas por sus filiales, y a cumplir con sus obligaciones de proteger y garantizar derechos humanos y el medio ambiente ${ }^{58}$.

Dorothy Mbabazi, fue una de las primeras personas a las que Total notificó en mayo de 2017, que se bloquearía el acceso a su tierra expropiada para la construcción del oleoducto, y que optó por un reasentamiento en otra zona que le ofreció la petrolera francesa. En mayo de 2019, cuando los funcionarios locales de Total finalmente llevaron a la Sra. Mbabazi a su nueva parcela de tierra, ella pidió un mejor acceso a las carreteras y a los servicios básicos antes de mudarse, pero Total no ha respondido a su petición ${ }^{59}$, argumentando que es responsabilidad de su subsidiaria implementar esas regulaciones.

Este caso es el primero que se juzgará en virtud de la nueva ley francesa de deber de vigilancia, que obliga a las grandes empresas a desarrollar planes de vigilancia y a garantizar prácticas sociales y medioambientales responsables en sus filiales y subcontratistas. Si los jueces fallan a favor de los demandantes, es probable que se ordene a Total publicar un nuevo plan de vigilancia. Los jueces también podrían ordenarle que tome medidas urgentes para evitar que las violaciones existentes continúen y que se produzcan nuevas violaciones sobre el resto de agricultores afectados. Tienen hasta el 30 de enero de 2020 para decidir, y no hay noticias sobre cual será la actitud procesal de las partes, pero será importante ver cómo se comportan todos los interesados en este juicio.

Pero hablábamos de varias vías de acción, de modo que vamos a prestar atención a las otras dos, en las que la falsedad en los informes de sostenibilidad alteran el mercado para todos lo implicados: empresas y consumidores. Dejando de lado las acciones que afectan estrictamente la competencia

58 Para más información: https://www.business-humanrights.org/en/6-ngos-file-lawsuitagainst-total-over-alleged-failure-to-respect-french-duty-of-vigilance-law-in-its-operationsin-uganda\#c201181.

59 Hay que señalar que el marco de reasentamiento fijado por Total para la adquisición de tierras especifica que los ugandeses deben ser compensados antes de que se les confisquen sus tierras. 
entre empresas, interesa ahora prestar la atención a los efectos que esta desinformación provoca.

Falsear la información sobre el desempeño empresarial a través de los informes de sostenibilidad o similares, equivale a falsear el juego de competencia entre empresas en los mercados y conlleva, entre otras consecuencias, a inducir (potencialmente) a error al consumidor final del producto por lo que, conforme a las legislaciones nacionales en el tema de protección del consumidor y sobre la competencia desleal, el Estado debería garantizar foros adecuados para determinar las responsabilidades e indemnizar por los daños derivados de dichas prácticas.

Esto lo decimos teniendo en cuenta que la información difundida por la empresa está siendo empleada con fines lucrativos, de reputación y de competitividad, pero al mismo tiempo, esta misma información esfundamental a la hora de orientar al usuario en la elección de uno u otro producto, atendiendo justamente a las modalidades de fabricación o distribución y al respeto a ciertos parámetros. En otras palabras, la información proporcionada por la empresa a través de sus informes de sostenibilidad está poniendo en las manos de los particulares y de los mercados la protección de los derechos humanos y de las normas laborales. Son por tanto los consumidores o clientes/importadores los que van a castigar (o premiar) a aquellas empresas que no sean transparentes en la gestión de su cadena de producción o las que tengan (o no) impactos sociales negativos en las comunidades en la que desarrollan sus actividades.

Por tanto, no es descabellado plantearse la ampliación de la legitimación a las asociaciones de consumidores cuando hablamos de estas prácticas desleales y plantear como propuesta para avanzar en su protección, ampliar y reforzar su legitimación pensando en estos supuestos. Esto permitiría tener resultados homogéneos y reducir los costes procesales, siendo tales costes un verdadero - casi insalvable - obstáculo para la tutela de los derechos e intereses colectivos. Es más, en junio de 2013 la Comisión Europea emitía una Recomendación a los Estados Miembros para que introdujeran en sus sistemas procesales mecanismos de tutela colectiva de los derechos e intereses de consumidores y usuarios ${ }^{60}$, advirtiendo expresamente (apartado VII «Supervisión y presentación de informes»), que los Estados miembros debían «aplicar los principios establecidos (en aquella) a sus sistemas nacionales de recursos colectivos el 26 de julio de 2017 , a más tardar».

${ }^{60}$ Recomendación de la Comisión de 11 de junio de 2013 sobre los principios comunes aplicables a los mecanismos de recurso colectivo de cesación o de indemnización en los Estados miembros en caso de violación de los derechos reconocidos por el Derecho de la Unión (2013/396/UE), DO L núm.201 de 26 de julio de 2013. 
A raíz del caso Dieselgate, generado entre otros motivos por la información fraudulenta presentada por Volkswagen sobre las emisiones contaminantes de sus vehículos, y que provocó afectados en todo el mundo, la Unión Europea se ha planteado reforzar de forma más contundente los derechos de los consumidores a través de una directiva sobre acciones en masa ${ }^{61}$. Desde la Comisión se indica que esta propuesta, bautizada como New Deal for Consumers ${ }^{62}$, debe ayudar a que el consumidor mantenga la confianza en las empresas en sus relaciones habituales, lo que ayudará a reforzar el concepto de mercado único interior. Así, además de ampliar la legitimación para entablar las acciones en masa, se pide multar a las empresas que incumplan derechos del consumidor con el $4 \%$ de sus ingresos anuales, cuando sus acciones provoquen daños generalizados al medioambiente y a las comunidades donde desarrollan sus actividades ${ }^{63}$.

Es solo el inicio pero tal vez con estos pequeños avances se consiga aunar la protección de derechos humanos con los derechos de los consumidores y se puede de algún modo mejorar el acceso a la justicia y por tanto, mejorar la situación de los más vulnerables.

\section{Conclusiones}

La demanda presentada en Francia contra la empresa Total, el primer caso basado sobre el incumplimiento del deber de vigilancia, por su responsabilidad indirecta que derivaría de las obligaciones establecidas en la Ley sobre el deber de vigilancia francesa, abre un camino nuevo y esperanzador. Lo que se pide es reconocer que la ley no se limita a pedir a las corporaciones la publicación de la información, sino también que la misma refleje la realidad de los impactos sobre el medio ambiente y los derechos humanos, tanto de la matriz como de sus filiales y de otras empresas que pertenecen al mismo grupo o que están bajo el su control. Es por ello por lo que creemos que esta acción legal marcará un punto de inflexión en la lucha a la impunidad corporativa.

Pero esta no es la única vía que se podría explorar para responsabilizar las corporaciones por sus actividades delictivas extraterritoriales; el derecho

${ }^{61}$ Más información en:https://confilegal.com/20180413-bruselas-plantea-reforzar-los-derechos-de-consumidores-con-una-directiva-que-impulse-las-acciones-colectivas/.

${ }^{62}$ Véase http://www .europarl.europa.eu/thinktank/en/document.html?reference=EPRS_ BRI(2018)623547.

${ }^{63}$ Más información en:https://eur-lex.europa.eu/legal-content/ES/TXT/PDF/?uri=CELE X:52018DC0183\&from=EN. 
de la competencia ya sea entre las propias empresas o en su relación con los consumidores, podría abrir las puertas a nuevas acciones o ampliaciones de legitimaciones que permitieran pedir responsabilidades o incluso sancionar por publicar datos falsos o deliberadamente erróneos o incompletos en sus reporting.

Es manifiestamente claro que la tendencia general acepta ya que las relaciones entre empresas y derechos humanos requieren de instrumentos jurídicos vinculantes. Y decimos esto porque la reticencia que se palpa desde la Unión Europea a un Tratado Vinculante y los retrocesos constantes de las Sesiones del Grupo de Trabajo Intergubernamental de Composición Abierta que tiene como objetivo este Binding Treaty no son sino muestras del interés en no llegar a una normativa de hard law. Si el sujetarse a normas estrictas, en el sentido de vinculantes, de control de promoción y protección de derechos humanos causa tanto desasosiego a las multinacionales es muestra de que es imprescindible alcanzar este objetivo, supranacional o nacional, que acabe con la sensación de impunidad diluida en la cadena de suministros. Solo en la medida que seamos capaces de implementar normas vinculantes podremos creer que la impunidad de las corporaciones internacionales tiene fecha de caducidad.

Pensamos que el reporting puede ser la punta de lanza que agriete la coraza empresarial porque es un instrumento que implementan como parte de su estructura empresarial. Saben que el consumidor actual se fija en las marcas y en su imagen corporativa y los informes de sostenibilidad les ayudan a proyectar una imagen de empresas comprometidas con el medio ambiente, alejadas de prácticas de esclavitud o defensoras de los derechos de los niños. Sabiendo esto deberíamos ser capaces de hacer de la necesidad virtud y exigir que esta imagen que pretenden dar a través del reporting en sentido extenso no solo se corresponda con la realidad, sino que en caso de no hacerlo conlleve sanciones jurídico-económicas cuantificables y materialmente exigibles.

Tenemos algunos ejemplos nacionales a seguir, ahí está la ley francesa o la holandesa, pero si son las corporaciones internacionales los verdaderos interlocutores se debería afrontar una regulación a nivel internacional. El peligro, como hemos visto en los diferentes Drafts que se han manejado en el seno de Naciones Unidas, es diluir la normativa en negociaciones con demasiados intereses en juego, cuando en realidad el objetivo único y último es la protección de los derechos humanos más elementales, y ese interés debería ser universal y ajeno a intereses empresariales. No debería ser imposible que la relación entre empresa y derechos humanos tuviera como consecuencia la impunidad. 


\section{Sobre las autoras}

Lorena Sales Pallarés, es Profesora Titular de Universidad de Derecho Internacional Privado, Facultad de Ciencias Sociales de Cuenca, de la Universitat de Castilla-La Mancha. Con anterioridad ha sido profesora de Derecho internacional privado en la Universitat Jaume I de Castelló, donde realizó sus estudios de Licenciatura, y defendió su Tesis Doctoral (Doctora cum laude por la Universitat Jaume I en 2002). Cuenta con más de 40 publicaciones entre libros, capítulos de libros y artículos en revistas especializadas sobre diversos temas que centran su labor investigadora. En este sentido y aunque su inicial línea de investigación fue el transporte marítimo y aéreo internacional, desde hace unos años trabaja fundamentalmente dos temáticas: las relaciones entre derechos humanos y empresas multinacionales y el derecho de familia internacional, cada una de las cuales sustentada por diversas publicaciones, seminario y proyectos de investigación nacionales y europeos (Proyecto Europeo «Human Rights in Business» entre 2014 y 2016). Además de participar como docente en diferentes masters oficiales, imparte conferencias a colectivos especializados y a diversas asociaciones profesionales, participando activamente en diversos grupos de trabajo dentro de la OIT dedicados a la esclavitud moderna. Recientemente participa en la creación y el impulso de la Red REDH-EXATA, redhexata.com.

María Chiara Marullo. Profesora Ayudante Doctor de Derecho Internacional Privado, Facultad de Ciencias Jurídicas y Económicas, Departamento de Derecho Privado de la Universitat Jaume I. Acreditada a Profesora Contratada Doctora. Miembro de la REDH-EXATA, redhexata.com. Doctora cum laude por la Universitat Jaume I (2014) y Premio Jaime Brunet a la mejor tesis doctoral a la promoción de los Derechos Humanos, Universidad Pública de Navarra (2016). Investigadora postdoctoral en la Facultad de Ciencias Jurídicas y Económicas, Departamento de Finanzas y Contabilidad. Grupos de investigación: «Sostenibilidad de las Organizaciones y Gestión de la Responsabilidad Social - Mercados Financieros» y «Derechos Humanos y Derechos Fundamentales». Investigadora en el proyecto «SMART Sustainable Market Actors for Responsible Trade» (20162020); colaboradora del proyecto «Constitución climática global: gobernanza y Derecho en un contexto complejo» (2017-2019) y investigadora en el Proyecto Europeo «Human Rights in Business» (2014-2016).

\section{About the authors}

Lorena Sales Pallarés, is Professor of International Private Law, at Faculty of Social Sciences of Cuenca, University of Castilla-La Mancha. 
Previously, she was Professor of Private International Law at the Universitat Jaume I de Castelló; BA in Law, and PhD in Law at the University of Jaume I (2002). She has more than 40 publications among books, book chapters and articles in specialized reviews on various topics that focus her research work. Although her initial line of research was maritime and aerial international transport, for the last few years she has been working mainly on two subjects: the relationship between human rights and multinational companies and international family law, each of which supporting by various publications, seminars and national and European research projects (European Project «Human Rights in Business» between 2014 and 2016). In addition to teaching in different official masters, he gives lectures to specialized groups and various professional associations, actively participating in various working groups within the ILO dedicated to modern slavery. Recently, she participates in the creation and promotion of the network REDH-EXATA, redhexata.com.

María Chiara Marullo. Assistant Professor of Private International Law, Law Faculty, Department of Private Law, Universitat Jaume I. Member of the network: REDH-EXATA, redhexata.com. Doctor cum laude from the Universitat Jaume I (2014) and Jaime Brunet Award for the best doctoral thesis for the promotion of Human Rights, Public University of Navarra (2016). Postdoctoral Researcher, Department of Finance and Accounting, Universitat Jaume I. Research group: «Sustainability of Organizations and Management of Social Responsibility - Financial Markets» and « Human Rights and Fundamental Rights». Researcher in the «SMART Sustainable Market Actors for Responsible Trade» European Project (20162020); collaborator in the project: «Global climate constitution: governance and law in a complex context» (2017-2019), and researcher in the European Project «Human Rights in Business» (2014-2016). 


\section{Derechos de autor}

Los derechos de autor (para la distribución, comunicación pública, reproducción e inclusión en bases de datos de indexación y repositorios institucionales) de esta publicación (Cuadernos Europeos de Deusto, CED) pertenecen a la editorial Universidad de Deusto. El acceso al contenido digital de cualquier número de Cuadernos Europeos de Deusto es gratuito inmediatamente después de su publicación. Los trabajos podrán leerse, descargarse, copiar y difundir en cualquier medio sin fines comerciales y según lo previsto por la ley; sin la previa autorización de la Editorial (Universidad de Deusto) o el autor. Así mismo, los trabajos editados en CED pueden ser publicados con posterioridad en otros medios o revistas, siempre que el autor indique con claridad y en la primera nota a pie de página que el trabajo se publicó por primera vez en CED, con indicación del número, año, páginas y DOI (si procede). Cualquier otro uso de su contenido en cualquier medio o formato, ahora conocido o desarrollado en el futuro, requiere el permiso previo por escrito del titular de los derechos de autor.

\section{Copyright}

Copyright (for distribution, public communication, reproduction and inclusion in indexation databases and institutional repositories) of this publication (Cuadernos Europeos de Deusto, CED) belongs to the publisher University of Deusto. Access to the digital content of any Issue of Cuadernos Europeos de Deusto is free upon its publication. The content can be read, downloaded, copied, and distributed freely in any medium only for non-commercial purposes and in accordance with any applicable copyright legislation, without prior permission from the copyright holder (University of Deusto) or the author. Thus, the content of CED can be subsequently published in other media or journals, as long as the author clearly indicates in the first footnote that the work was published in CED for the first time, indicating the Issue number, year, pages, and DOI (if applicable). Any other use of its content in any medium or format, now known or developed in the future, requires prior written permission of the copyright holder. 